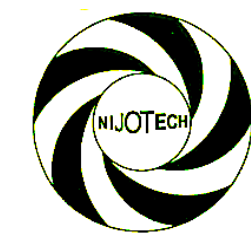

Nigerian Journal of Technology (NIJOTECH)

Vol. 39, No. 1, January 2020, pp. 15 - 24

Copyright@ Faculty of Engineering, University of Nigeria, Nsukka,

Print ISSN: 0331-8443, Electronic ISSN: 2467-8821

www.nijotech.com

http://dx.doi.org/10.4314/njt.v39i1.2

\title{
ACTUARIAL MODELLING OF EQUILIBRIUM CONDITION IN LIFE AND PENSION USING INTEGRAL TRANSFORM
}

\author{
G. M. Ogungbenle ${ }^{1, *}$, and J. S. Adeyele ${ }^{2}$ \\ 1,2, DePARTMENT OF ACtUARIAL SCIENCE, UniverSity OF Jos, PLATEAU STATE, NIGERIA \\ E-mail addresses; ${ }^{1}$ gbengarising@gmail.com, ${ }^{2}$ adesolojosh@gmail.com
}

\begin{abstract}
This paper aims at deriving actuarial modelling of equilibrium condition in life and pension mathematics under the framework of integral transform. The specific objective is to establish net actuarial balance representing the difference between the present values of contributions and benefit outgo of the defined benefit scheme. This is the equilibrium position such the plan sponsor cannot borrow to pay plan members at the point of retirement. Our investigation confirms that the present value of benefit outgo payable by the trustees equals the present value of total contribution of the plan sponsor so that the equilibrium point is reached under the framework of integral transform.
\end{abstract}

Keywords: Integral transform, defined benefit, force of interest, equilibrium Fredholm, liability and Thiele

\section{BACKGROUND INFORMATION}

Integral equations evolve in diverse subfield of actuarial mathematics and numerous applications in life insurance and pension valuation, life contingency mathematics, ruin probabilities, game theory, stochastic optimal control problems in pensions and mathematics of finance especially in the determination of actuarial present value at equilibrium position [1]. Equilibrium is the level at which the present value of benefit outgo exactly match the present value of contribution. At this point these two present values have the same integral transforms. In other words, it is a zero of an integral transform which does not vary with time. [1] argues further that all exact closed-form zeros of integral equations play powerful role in deep understanding of quantitative characteristics of equilibrium and processes in many areas of actuarial science. Integral equations as they evolve in mathematics of pensions consist of functions which are derivable from both mathematical analysis and actuarial experiments and are not strictly fixed. It is necessary to choose and examine the structure of these equations so to find an easy method of analysis and solution. The exact solutions will be used to confirm the validity, consistency and estimate errors of some numerical and asymptotic methods. The problem of funding a defined benefit scheme is that of estimating the initial and subsequent rates of contribution at a level mutually, collectively agreed and affordable to both the plan sponsor and plan members but at the same time plough back the accumulated reserve to the projected investment needs [2]. When a defined benefit plan is set up by the trustees based on the advice of a pension actuary, the major problem which the trustees need to track down include the method of financing the scheme and the determination of the rate of contribution. According to [3], funding is the method by which financial resources are raised to meet the expenses on the plan without differentiating plan sponsor and plan members. In this way, it defines a systematic way of raising the adequate cash necessary to meet the financial obligations of a defined benefit. It is a chosen method of financing long term pensions of defined benefit scheme structure. Such methods usually differ in the timing of contribution payments for the purpose of financing present and future pension obligations.

The funding system is functionally dependent on and is governed by both the amount and timing of the plan sponsor contributions to the plan. In [4], it was argued that the funding policy for a defined benefit scheme would then result in a set of algorithm applied in computing the annual rate of contributions

\footnotetext{
* Corresponding author, tel: +234 8165562939
} 
which the plan sponsor will pay within a particular year. The contribution rate comprise of the aggregate financial resources allocated to the defined benefits plan by either the sponsor or the insured plan members. For a defined benefit plan funding policy, the aggregate contribution requirement is equivalent to the normal cost of providing accrued benefits for plan members in service over the year including the amortization payment schedule of the implicit pension debt representing an unfunded actuarial liability for that year. In other words the employer's contribution is the sum of normal cost plus amortization less employee contributions. A funding policy is not meant to change significantly on a yearly basis but rather should address the means and period of time through which investment expenses are paid. Since the actuarial cost method such as projected unit method (PUC) technically allocates the subsisting total present value of future benefits over the current plan members' working careers, the funding policy would then describe the numerical calculation of actuarial accrued liabilities together with the present value of future normal costs. [3] argues that in order to address the problem of disequilibrium, the funding policy together with actuarial cost methods should deal appropriately with cases where there are insufficient assets to fund retirees' liabilities. It is the funding policy which actually determines the appropriate asset smoothing methods applied to recognize profit and loss in pension assets over the time whether it should be open or closed and deviation of the funding value from the market value of asset.

\section{DEFINED BENEFITS SCHEME UNDER INSURED ENVIRONMENT}

Following [5], the actuarial measurement of both public and occupational pension liabilities and contribution requirements is very sensitive to actuarial assumptions which are usually considered when addressing the financial position of any pension system. The trend of the sensitivity of liability and contribution valuations to actuarial demographic and economic statistics and methods is dependent on the actuarial data profile of pension participants.

According to [3], prospective reserve is the excess of the expected discounted future contribution at a point in time expressed as the policy value over expected discounted future benefits outgo. A policy value must be established as an integral part of defined benefits system. A defined benefit scheme and its derivatives may be obtained by choice vides life assurance contracts purchased on the lives of plan members. Contributions are paid by plan sponsor to the life office and the benefits accruing from the life assurance contracts are paid by the insurer through the trustees to the qualified beneficiaries at separation. In order to compute the actual contribution payable to the life office, actuarial valuation is required so that the actuarial liabilities (AL) which represents a fraction of the present value of actuarial liability (PVAL) can form a proportion of the life office technical provisions. This arrangement is employed when a defined benefits pension scheme is set up. The defined benefit plan is not usually set up on a fully allocated basis where mobile retirement savings accounts (MRSA) is assigned to every member of the plan. The provision of group life assurance cover could be applied to finance defined benefit scheme in the event where defined benefit plan is allowed on non-allocated financing. In a defined benefit plan contract, the retirement benefits are usually promised ahead of retirement to fall in line with a predetermined pay out equation defined by the actuary for the life offices or the trustees and contributions are calculated to maintain the fund in equilibrium. However, for a defined contribution plans such as insured deposit administration scheme, contribution rate as percentage of salary are defined initially and the benefits rely on the investment returns on the funds. The financial, volatility and investment risk characterizing defined benefit contract relatively differs from that of defined contributions. The benefits accrued are defined in clear terms by observing that the working population contributions is the endogenous variable while the contributors all face the risk. A clear edge of defined benefit plans from the plan members' sense of judgment is the stability of replacement rates (the ratio of the amount of the pension benefit to the amount of the insurable earnings) of income that the plans generate. The insurance against both annual income earnings and benefit risk that workers obtain is a pointer that the plan sponsor assumes the total risks. Larger employment work force plan sponsor can diversify real wage risk unlike scheme members hence the stable replacement rate is an advantage of defined benefit scheme.

In a defined benefit scheme, the fund manager completely assumes the risk of poor investment portfolio and wrongly selected portfolio mix. The major challenge is how to determine the actual rate 
of contribution including the minimum funding level which bears a functional relationship to the actual accrued liability in a way that may guarantee the promised benefits. The contract is set up and managed with the contributions and earnings on investments. The solvency and contribution rate risks are twin paramount risks relating to investment of the assets which must be squarely addressed to ensure the stability and security of the scheme. Defined benefit plans are better seen as schemes where the member's pension benefit is obtained by an equation taking cognizance of the numbers of service years. Following [6], the argument for defined benefit pension systems lies in the fact that it has both the intra-generational and inter-generational risk sharing structure because the investment return on the system's structure is acutely low as a result of the accumulation of unfunded liabilities. The implication is that the infinitesimally low returns could not be attributable to its defined benefit nature. In essence the task to deal with is the latent underfunding but not the structure of the system. To solve this problem, some legislation have been passed to either review downwards the benefits which retirees are entitled to receive at separation or increasing the retirement age. The policy of upward review of the normal retirement age has a very pervasive impact on health and health insurance structure and may in fact result in longevity risk. The underfunding problem of defined benefit system is a very critical issue addressed by some reforms providing motivation as a leeway for individual to save against the future through mobile retirement savings account of defined contribution system. Many defined benefit plans and derivatives can be combined with a form of social security insurance scheme to which a member is entitled to have integrated structure. The defined benefit plan can be analyzed from the deterministic or stochastic dimensions. A valuation process will be deterministic if its functional value can be predetermined

In this paper, a simple continuous time deterministic model for the reserve of a defined benefit pension fund is discussed, with the intent to establishing a financial equilibrium condition. To start with, the following conditions are assumed on defined benefits. (i)Salaries grow every year in accordance with the rate of wage escalation $r_{e}$ (ii) At the beginning of the year $(t, t+1) a$ new entrant is enlisted into the scheme at entry age $e$, with a wage income at age y denoted by ${ }^{w_{y}}$.

(iii) The members remain in the scheme till the normal retirement age $R$ and mortality prior age $R$ is assumed to be infinitesimally small approaching zero. i.e. $R(\omega)=0$, where $\omega$ is the limit of life in the life table.

(iv) At retirement age $\mathrm{R}$, a member may retire and then receives retirement benefits equivalent to a proportion of the final salary for each of the years in service as a scheme member and usually paid every year in advance till death. This type of pension structure is usually secured provided the scheme member will purchase life annuity contract after retirement from a life office where the benefits obligation can be converted to life annuity fund so as to obtain insurance cover for his pension. As a fallout from purchasing life annuity, the original pension fund manager bears no financial responsibility to disburse further payments to the scheme member as payments automatically cease upon converting to annuity.

\subsection{The Wage Income Model}

In view of [7], insurance of defined benefit schemes are typically long term contract where a life office accepts risk from the insured by receiving the contributions and then paying benefit at separation. Under defined benefit final salary insured schemes, retirement benefit income is set at par to a proportion of the final salary to avoid income shocks at retirement age, this calculation is probably reasonable to prevent retirement income from suffering from any shocks just before retirement age. This is obtainable by approximating and equating retirement income to be a fraction of mean wage income over the last few years in particular the three to five years preceding retirement age. Some assumptions are usually formulated about the variables of interest otherwise known as demographic and economic statistics. Life insurance contracts of which defined benefit scheme is a branch, depend on death or survival of the insured life $(x)$ and also on these economic and demographic statistics because the contributions or premiums are usually invested to receive earnings so as to meet future benefits obligations. The valuation of a defined benefits scheme in force at a time $t$, is required to establish the solvency of the fund.

Vol. 39, No. 1, January 2020 
$w(y+t)=$ the wage income at age $\mathrm{y}$ in further time $\mathrm{t}$

$r(t)=$ the rate of return on pension fund, which is defined as the annual pension benefits received as a share of total lifetime working income

$r(t)=$ contribution rate

${ }_{t} p_{x}=$ probability that a life aged $\mathrm{x}$ survives employment to age $(\mathrm{x}+\mathrm{t})$,

$\mathrm{R}=$ retirement age

$\mathrm{e}=$ entry age

$\omega$ = limit of life

We assume that the functions $w_{y+t},{ }_{t} p_{x}$ and $c_{t}$ are continuous and differentiable.

The total monthly payroll for gratuity is given by $\frac{\left(1+r_{e}\right)^{t} \int_{e}^{R} E\left(L_{y}\right) w_{y} d y}{m}, e<y<R$

where $e, r$ denote the entry age, retirement age and $\mathrm{m}$ is the 12 months calendar year respectively. Following [7], Let $\mathrm{w}_{\mathrm{y}}$ be the promotional wage of an employee at age $y$ and let $w_{y}(t)$ be the pensionable wage function at a further time $t$.

Then $w_{y}(t)=e^{t \ln \left(1+r_{e}\right)} \times w_{y}=\left(1+r_{e}\right)^{t} \times w_{y} \quad$ where

$r_{e}$ is the rate of wage escalation.

Therefore, $\frac{w_{y}(t+1)}{w_{y}}=\frac{w_{y}\left(1+r_{e}\right)^{(1+t)}}{\left(1+r_{e}\right)^{t} w_{y}}=\left(1+r_{e}\right)^{1}, y=e, e+1, e+2$,

The rate of change in wage with respect to time is $\mathrm{W}_{\mathrm{y}}{ }^{\prime}(\mathrm{t})=\ln \left(1+\mathrm{r}_{\mathrm{e}}\right) * \mathrm{~W}_{\mathrm{y}} * \mathrm{e}^{\mathrm{tln}\left(1+\mathrm{r}_{\mathrm{e}}\right)}$

If the gratuity is set up at initial time, then $t=0$, and the initial change in wage is independent of time as $\mathrm{W}_{\mathrm{y}}{ }^{\prime}(0)=\ln \left(1+\mathrm{r}_{\mathrm{e}}\right) * \mathrm{~W}_{\mathrm{y}}$ but $w_{y}(0)=\ln \left(1+r_{e}\right)^{0} w_{y}=w_{y}$, so that

$$
w_{y}^{\prime}(0)=w_{y}(0) \ln \left(1+r_{e}\right)
$$

$\frac{w_{y}^{\prime}(0)}{w_{y}(0)}=\ln \left(1+r_{e}\right) \Rightarrow d \ln w_{y}(0)=\ln \left(1+r_{e}\right)$

Then $w_{y}(t)=e^{t \ln \left(1+r_{e}\right)} \times w_{y}(0)$
The number of active member within the ages $y$ and $(\mathrm{y}+\delta \mathrm{y})$ is $\mathrm{E}[\mathrm{L}(\mathrm{y})] \delta \mathrm{y}=1_{\mathrm{y}} \delta \mathrm{y}$ where $\mathrm{L}(\mathrm{y})$ is binomially distributed and the random variable $1_{\mathrm{y}}$ is the number of active members who survive employment to age $y$.

The mean number of active members who survive employment to age $y$ is $l_{o} \times_{t} p_{0} y=l_{0} \times_{y} p_{0}$ where $y$ is the random life time.

Total employee age related wage $=\mathrm{E}[\mathrm{L}(\mathrm{y})] w_{\mathrm{y}}$.

Escalated total employee age related wage $=$ $\mathrm{E}[\mathrm{L}(\mathrm{y})]\left(1+r_{e}\right)^{1} w_{\mathrm{y}}$

The total gratuity employee wage for computation for all ages $=\int_{\mathrm{e}}^{\mathrm{R}} \mathrm{E}[\mathrm{L}(\mathrm{y})]\left(1+r_{e}\right)^{t} w_{\mathrm{y}} d y$ $\mathrm{E}_{\mathrm{S}}^{A}=\sum_{\mathrm{y}=\mathrm{e}}^{\mathrm{R}} \mathrm{w}_{\mathrm{y}}(t)=\left(1+r_{e}\right)^{t} \int_{e}^{R} l_{y} w_{\mathrm{y}} d y$ , where $\mathrm{e}$ and $\mathrm{R}$ are the entry and retirement ages respectively and $\mathrm{E}_{\mathrm{S}}^{A}$ is the total escalated wage for all ages. Usually $\mathrm{E}_{\mathrm{S}}^{A}$ represents annual total wage hence for computational purposes it must be divided by 12 , hence,

$$
\frac{\mathrm{E}_{\mathrm{S}}^{A}}{m}=\frac{\left(1+r_{e}\right)^{t}}{m} \int_{e}^{R} E[L(y)] w_{\mathrm{y}} d y=\frac{\left(1+r_{e}\right)^{t}}{m} \int_{e}^{R} l_{y} w_{\mathrm{y}} d y,
$$

\section{.} (n) 
wage level at the beginning of the plan set up is defined as a monetary unit, then the level of wages at time $t$ would be of the form $e^{r_{c} t}$ so that a unit defined benefit value would correspondingly grow to $e^{r_{e} t}$ in $\mathrm{t}$ years.

\section{INTEGRAL EQUATION AND ITS RELATIONSHIP TO EQUILIBRIUM CONDITION FOR A LIFE AGED y}

The problem of equilibrium determination could be dealt with analytically. Given the infinite nature of the problem a solution exists and can be obtained by integral transform. We define a kernel function $\mathrm{K}(\mathrm{y}$, t) mathematically as

Let $K:[a, b] \times[a, b] \rightarrow R$ be continuous and that a, $\mathrm{b}$ are real constants.

$$
\begin{aligned}
& V: K \rightarrow R \text { such } \\
& \Delta v(t)=v(t) \delta \Delta t+C(t) W(t) \Delta t-f(t) \Delta t \\
& V(y)=h(y)+\lambda \int_{a}^{b} K(y, t) V(t) d t \text { is defined as }
\end{aligned}
$$

Fredholm integral equation, where $\lambda$ is real.

The expression $K(y, t)$ in the equation above is the kernel of the integral equation. The kernel will be symmetric if $K(y, t)=K(t, y)$, for all $\mathrm{x}, \mathrm{t} \in[\mathrm{a}, \mathrm{b}]$.

If $K:[a, b] \times[c, d] \rightarrow R$ is continuous, then by Fubini's theorem, the double integrals below exactly coincide, that is

$$
\int_{a}^{b} \int_{c}^{d} K(y, t) d y d t=\int_{c}^{d} \int_{a}^{b} K(y, t) d y d t \text { for }
$$

real

constants $\mathrm{a}, \mathrm{b}, \mathrm{c}$ and $\mathrm{d}$

The value of the $\lambda$ at which the homogeneous Fredholm equation has an identically non-zero solution $v=v(y)$ on in the interval [a, b] is the characteristic value of that equation and such a nonzero solution $v=v(y)$ is the eigen-function corresponding to $\lambda$.

Two important foundational continuous functions used in the mathematical analysis of a defined benefit scheme are the insured salary function $\mathrm{W}(\mathrm{t})$ and the benefit function $f(t)$. Both functions of time $t$ are assumed to be continuous and differentiable. The total benefit expenditure $f($.$) and the total insured$ salary $\mathrm{W}($.$) in the time interval (\mathrm{t}, \mathrm{t}+\Delta \mathrm{t})$ is obtained as $\mathrm{B}(\mathrm{t}) \Delta \mathrm{t}$ and $\mathrm{w}(\mathrm{t}) \Delta \mathrm{t}$

Let $f(t)$ be the defined benefit function

$\Delta \mathrm{t}$ be a small time interval

$\mathrm{w}(\mathrm{t})$ be the salary function

In $[3,7]$, if $\mathrm{C}(\mathrm{t})$ is the contribution rate function. It is sufficient that $\mathrm{C}(\mathrm{t})>0$, otherwise the trustees may be reimbursing contributions.

$v(t)$ be the reserve function constituting the excess of inflow over outflow and accumulated at force of interest $\partial$. We assume $\mathrm{C}(\mathrm{t})>0$ otherwise the trustees may be borrowing to pay benefit and enter ruin.

\section{FUNDING OF DEFINED BENEFIT SCHEME THE CONTINUOUS FORCE OF INTEREST}

The actuarial requirements of both public and occupational pensions have drawn significant attention of pension actuaries and pension managers recently especially in the areas of reforms. Much attention focus on how would actuarial assumptions and methods affect the accuracy of pension liabilities and the adequacy of sponsor funding practices. National Association of State Retirement Administrators [8] was of the opinion that public pensions should continually use discount rates which will reflect investment performance returns while [9, 10] were of divergent opinions to choose actuarial discount rates which fall in line with the certainty of future benefit payments rubrics.

Following Macdonald [11], Let $A\left(t_{1}, t_{3}\right)$ be the accumulation factor at time $t_{3} \geq t_{1}$ and $v\left(t_{1}, t_{3}\right)$ be the corresponding discount factor

$$
v\left(t_{1}, t_{3}\right)=\frac{1}{A\left(t_{1}, t_{3}\right)}
$$

Since interest is compound, $A\left(t_{1}, t_{3}\right)=A\left(t_{1}, t_{2}\right) A\left(t_{2}, t_{3}\right)$ for $t_{1} \leq t_{2} \leq t_{3}$

$\delta(t)=\frac{1}{\left[A\left(0, t_{1}\right)\right]} \frac{d A\left(0, t_{1}\right)}{d t_{1}}$

$\left.\delta(t)=\frac{1}{\left.\int_{0}^{t_{1}} \delta\left(t_{s}\right)\right] d t_{s}} \frac{d A\left(0, t_{1}\right)}{d t_{1}}, A\left(0, t_{1}\right)=\int_{0}^{t_{1}} \delta\left(t_{s}\right)\right] d t_{s}$

When $\delta\left(t_{1}\right)=\delta$ then $(1+j)=e^{\delta}$

The scheme will be fully funded if the objective is to raise reserves equal to the total amount of accrued liabilities. Valuation inputs such as discount, salary 
escalation rates, cost methods and life mortality tables all have effect on funding ratios and contribution level. The effect must be deeply addressed so that bias will not be introduced to the relative comparison of funding ratios of pension structures. The economic and demographic statistics is a major determinant factor on the level of funding ratios and contribution computations. It is noted that a pension scheme can adjust upwards the required contributions by increasing the discount rate assumption while the funding condition sharply drops in the end. However, when the system decreases its discount rate while still maintaining investment returns at a steady state threshold which was hitherto assumed, it will definitely take a fairly long time before the funding ratio will return to its initial level and the annual required contribution may correspondingly take a longer time to return to its actual level but the exact time length interval depends on the investment returns.

$\Delta \mathrm{v}(\mathrm{t})=\mathrm{V}(\mathrm{t}) \delta \Delta \mathrm{t}+\mathrm{C}(\mathrm{t}) \mathrm{W}(\mathrm{t}) \Delta \mathrm{t}-\mathrm{f}(\mathrm{t}) \Delta \mathrm{t}$

As $\Delta \mathrm{t} \rightarrow \mathrm{o}(1)$ where $\mathrm{O}(1)$ is any function tending to zero, we have

$\mathrm{dv}(\mathrm{t})=\mathrm{v}(\mathrm{t}) \delta \mathrm{dt}+\mathrm{C}(\mathrm{t}) \mathrm{W}(\mathrm{t}) \mathrm{dt}-\mathrm{f}(\mathrm{t}) \mathrm{dt}$.

The change in the reserve in any small interval is equal to the addition of investment return on the reserve in the interval and excess of contribution over benefit in the same time interval.

$$
\begin{aligned}
\frac{\mathrm{dV}(\mathrm{t})}{d t} & =\delta \mathrm{V}(\mathrm{t})+\mathrm{C}(\mathrm{t}) \mathrm{W}(\mathrm{t})-\mathrm{f}(\mathrm{t}) \\
\mathrm{V}^{\prime}(\mathrm{t}) & =\delta \mathrm{V}(\mathrm{t})+\mathrm{C}(\mathrm{t}) \mathrm{W}(\mathrm{t})-\mathrm{f}(\mathrm{t}) \\
\mathrm{V}(0) & =0, \mathrm{~V}^{\prime}(0)=\mathrm{C}(\mathrm{t}) \mathrm{W}(\mathrm{t})-\mathrm{f}(\mathrm{t})
\end{aligned}
$$

The integrating factor is:

$\mathrm{I}(\mathrm{t})=\mathrm{e}^{\int \mathrm{p}(\mathrm{t}) \mathrm{dt}}=\mathrm{e}^{-\int \delta \mathrm{dt}}=\mathrm{e}^{-\delta \mathrm{t}}$

$$
\begin{aligned}
& \int_{a}^{b} \frac{d}{d t}\left[\frac{e^{-\delta t} \mathrm{dv}(\mathrm{t})}{\mathrm{dt}}\right] d t=\int_{a}^{b}\left[e^{-\delta t} C(t) w(t)-f(t) e^{-\delta t}\right] d t \\
& {\left[e^{-\delta t} \mathrm{dv}(\mathrm{t})\right]_{\mathrm{a}}^{\mathrm{b}}=\int_{a}^{b}\left[e^{-\delta t} C(t) w(t)-f(t) e^{-\delta t}\right] d t} \\
& e^{-\delta b} \mathrm{v}(\mathrm{b})-e^{-\delta a} \mathrm{v}(\mathrm{a})=\int_{a}^{b}\left[e^{-\delta t} C(t) w(t)-f(t) e^{-\delta t}\right] d t \\
& e^{-\delta b} \mathrm{v}(\mathrm{b})=e^{-\delta a} \mathrm{v}(\mathrm{a})+\int_{a}^{b}\left[e^{-\delta b} C(t) w(t)-f(t) e^{-\delta b}\right] d t \\
& \mathrm{v}(\mathrm{b})=e^{\delta b-\delta a} \mathrm{v}(\mathrm{a})+\int_{a}^{b}\left[e^{-\delta b} C(t) w(t)-e^{-\delta b} f(t) e^{-\delta t}\right] d t \\
& \mathrm{v}(\mathrm{b})=e^{\delta b-\delta a} \mathrm{v}(\mathrm{a})+e^{-\delta b} \int_{a}^{b}\left[C(t) w(t)-1^{*} f(t) e^{-\delta t}\right] d t
\end{aligned}
$$

The limits of integration $a$ and $b$ are real usually and $a=0, b=\infty$ or $a=-\infty, b=\infty$

for life $(y)$, the integral is of the form

$\mathrm{v}(\mathrm{y})=f(y)+\lambda \int_{a}^{b} K(y, t) v(t) d t$

$\mathrm{v}(\mathrm{t})$ is not usually known but $K(y, t)$ is a known function

and substituting $\mathrm{y}=\mathrm{b}$ in $\mathrm{v}(\mathrm{y})$

$$
\begin{aligned}
& \mathrm{v}(\mathrm{b})=f(\mathrm{~b})+\lambda \int_{a}^{b}[K(b, t) V(t)] d t \text { where } \mathrm{f}(\mathrm{b})=e^{\delta b-\delta a} \mathrm{v}(\mathrm{a}) \\
& \mathrm{v}(\mathrm{b})=f(\mathrm{~b})+\lambda \int_{a}^{b}[C(t) w(t)-1 \times f(t)] \times e^{-\delta t} \mathrm{dt}
\end{aligned}
$$

following [12] ,in the event $\mathrm{v}(\mathrm{t})$ is not known in (1),

$$
\begin{aligned}
& \lambda_{1}=\frac{1}{\sqrt{R_{1}^{2}-R_{3} R_{2}}} \text { and } \lambda_{2}=\frac{-1}{\sqrt{R_{1}^{2}-R_{3} R_{2}}} \\
& R_{1}=\int_{a}^{b} C(y) w(y) d y, R_{2}=\int_{a}^{b} C^{2}(y) d y, R_{3}=\int_{a}^{b} w^{2}(y) d y
\end{aligned}
$$

$\frac{\mathrm{I}(\mathrm{t}) \mathrm{dv}(\mathrm{t})}{\mathrm{dt}}-I(t) \delta v(t)=I(t) C(t) w(t)-I(t) f(t)$ but $\mathrm{I}(\mathrm{t})=e_{\mathrm{v}(\mathrm{b})}^{-\delta t}=f(\mathrm{~b})+\lambda\left[B_{1} C(y) w(t)+B_{2} w(y)\right]$

Multiplying both sides by $v^{t}$

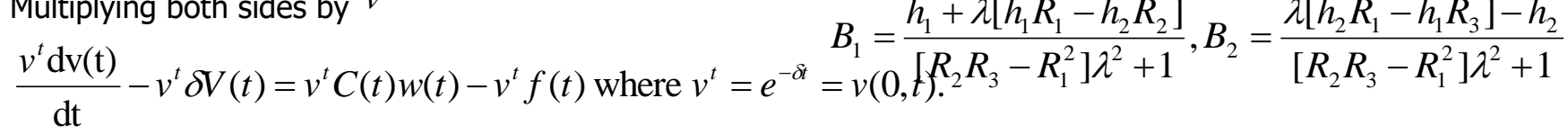

$\frac{e^{-\delta t} \mathrm{dv}(\mathrm{t})}{\mathrm{dt}}-e^{-\delta t} \delta v(t)=e^{-\delta t} C(t) w(t)-e^{-\delta t} f(t)$

$\frac{d}{d t}\left[\frac{e^{-\delta t} \mathrm{dv}(\mathrm{t})}{\mathrm{dt}}\right]=e^{-\delta t} C(t) w(t)-f(t) e^{-\delta t}$

Integrating between intervals $\mathrm{a} \leq \mathrm{t} \leq \mathrm{b}$ $h_{1}=\int_{a}^{b} C(y) f(y) d y, h_{2}=\int_{a}^{b} w(y) f(y) d y$

$\lambda=e^{\delta b}$ and $K(b, t)=C(t) w(t)-f(t)$ implies that the kernel function is symmetric. The kernel is also degenerate since it has the form $K(y, t)=C(t) w(t)-1 \times f(t)$ 
Substituting, $\mathrm{a}$ in $\mathrm{f}(\mathrm{b})=e^{\delta b-\delta a} \mathrm{v}(\mathrm{a})$, we have $\mathrm{f}(\mathrm{a})=\mathrm{v}(\mathrm{a})$ and we can re-write the equation $\mathrm{v}(\mathrm{b})=f(\mathrm{~b})+\lambda \int_{a}^{b}[K(b, t) v(t)] d t$ in the form $\mathrm{v}(\mathrm{b})=f(\mathrm{a})+\lambda \int_{a}^{b}[K(b, t) v(t)] d t$

For a defined befit scheme, the reserve at the time the scheme was set up is assumed zero and so the $\lim _{a \rightarrow 0} V(a)=0$

$$
\begin{aligned}
& \mathrm{v}(\mathrm{b})=f(\mathrm{~b})+\int_{a}^{b}\left[e^{\delta b-\delta t} \mathrm{C}(t) w(t)-e^{\delta b-\delta t} \mathrm{f}(t)\right] d t= \\
& =\int_{a}^{b}\left[e^{-\delta(b+t)} \mathrm{C}(t) w(t)-e^{-(\delta(b+t)} \mathrm{f}(t)\right] d t
\end{aligned}
$$

Using the linear transformation $\tau=b+t$, then $d \tau=d t$ and $\tau=\mathrm{a}+\mathrm{b}$ and $\tau=2 \mathrm{~b}$, we have $\mathrm{v}(\mathrm{b})=\int_{a+b}^{2 b}\left[e^{-\delta \tau} \mathrm{C}(\tau-b) w(\tau-b)-e^{-\delta \tau} \mathrm{f}(\tau-b)\right] d \tau$ is of the form $\int_{c}^{d}\left[e^{-\delta \tau} C(\tau-b) W(\tau-b) d \tau-\int_{a+b}^{2 b} e^{-\delta \tau} f(\tau-b)\right] d \tau$. $\frac{\mathrm{v}(\mathrm{b})}{\mathrm{e}^{\delta \mathrm{b}}}=\int_{\mathrm{a}}^{\mathrm{b}}\left[\mathrm{e}^{-\delta \mathrm{t}} \mathrm{C}(\mathrm{t}) \mathrm{W}(\mathrm{t})-\mathrm{e}^{-\delta \mathrm{t}} \mathrm{f}(\mathrm{t})\right] \mathrm{dt}$ and taking $\mathrm{a}=$ 0 . Since a defined benefit scheme has a long term liability, we evaluate $V(b)$ at infinity. The term $e^{\delta b}$ represents the maximum reduction factor in reserve to establish the actuarial equilibrium position.

$\lim _{b \rightarrow \infty} \frac{v(b)}{e^{\delta b}}=\int_{0}^{\infty}\left[e^{-\delta t} C(t) W(t)-e^{-\delta t} f(t)\right] d t$

$$
\lim _{b \rightarrow \infty} \frac{V(b)}{e^{\delta b}}=0
$$

$\int_{0}^{\infty}\left[\mathrm{e}^{-\delta \mathrm{t}} \mathrm{C}(\mathrm{t}) \mathrm{W}(\mathrm{t})-\mathrm{e}^{-\delta \mathrm{t}} \mathrm{f}(\mathrm{t})\right] d \mathrm{t}=0$

This implies that the net actuarial balance representing the difference between the present values of contributions and benefit outgo of the defined benefit scheme should be zero. Technically speaking actuarial balance is computed relative to an income rate as a ratio of contribution income to insurable earnings and a cost rate representing the ratio of total expenditure to insurable earnings [13]. The actuarial balance is then defined by comparing the income rate with the expenditure cost rate over a specified period [14]. Thus we have

$$
\int_{0}^{\infty} e^{-\delta t} C(t) W(t) d t=\int_{0}^{\infty} e^{-\delta t} f(t) d t
$$

The expected discounted continuation value of contribution is same as the present value of future benefit outgo [15]. In real sense the actuarial reserve functions are stochastic in nature.
Let $1_{B}$ be a indicator random variable of an event $B$. $1_{B}=1$ if $B$ occurs and $1_{B}=0$, if otherwise and by definition

$$
\mathrm{E}\left(1_{\mathrm{B}}\right)=1 \times \mathrm{P}(\mathrm{B})+0 \times \mathrm{P}(\mathrm{B})=\mathrm{P}(\mathrm{B})
$$

Having defined the indicator function for ease of understanding, then in the actuarial sense and following the introduction of this indicator function, it is sufficient as the next step to take the expectation of the indicator function $1_{\{\mathrm{T}(\mathrm{y}) \geq \mathrm{t}\}}$ which equals the probability that a life aged $y$ will survival to age $(y+$ t), i.e ${ }_{t} P_{y}=\frac{\operatorname{Pr}(Y>y+t)}{\operatorname{Pr}(Y>y)}=\frac{s_{T}(t+y)}{S_{T}(y)}$ where $l_{y}=l_{0} S_{Y}(y)$

$\frac{\mathrm{s}_{\mathrm{T}(\mathrm{t}+\mathrm{y})}}{\mathrm{S}_{\mathrm{T}}(\mathrm{y})}=\frac{\exp \left[-\int_{0}^{\mathrm{y}+\mathrm{t}} \alpha(\mathrm{u}) \mathrm{du}\right]}{\exp \left[-\int_{0}^{\mathrm{y}} \alpha(\mathrm{u}) \mathrm{du}\right]}=\exp \left[-\int_{\mathrm{y}}^{\mathrm{y}+\mathrm{t}} \Psi(\mathrm{u}) \mathrm{du}\right] \quad$, $\Psi(\mathrm{u})$ is the force of mortality

Let $\mathrm{T}(\mathrm{y})$ be the future lifetime function. $\mathrm{T}(\mathrm{y})=\mathrm{Y}-$ $\mathrm{y} \mid \mathrm{Y}>\mathrm{y}=\operatorname{Pr}(\mathrm{T}(\mathrm{y})>\mathrm{t})=\operatorname{Pr}(\mathrm{Y}=\mathrm{y}+\mathrm{t} \mid \mathrm{Y}>\mathrm{y})$

$\mathrm{E}\left[\int_{0}^{\infty} \mathrm{e}^{-\delta \mathrm{t}} \mathrm{C}(\mathrm{t}) \mathrm{W}(\mathrm{t}) \mathrm{dt}\right]=$ $\mathrm{E}\left[\int_{0}^{\infty} \mathrm{e}^{-\delta \mathrm{t}} \mathrm{C}(\mathrm{t}) \mathrm{W}(\mathrm{t}) 1_{\{\mathrm{T}(\mathrm{y}) \geq \mathrm{t}\}} \mathrm{dt}\right]=$ $\int_{0}^{\infty} \mathrm{e}^{-\delta \mathrm{t}} \mathrm{C}(\mathrm{t}) \mathrm{W}(\mathrm{t}) \mathrm{E}\left\{1_{\{\mathrm{T}(\mathrm{y}) \geq \mathrm{t}\}}\right\} \mathrm{dt}$ if $\quad t>$ $\mathrm{T}(\mathrm{y})$, the indicator function equals zero

$\mathrm{E} \int_{0}^{\infty} \mathrm{e}^{-\delta \mathrm{t}} \mathrm{C}(\mathrm{t}) \mathrm{W}(\mathrm{t}) \mathrm{dt}=\int_{0}^{\infty} \mathrm{e}^{-\delta \mathrm{t}} \mathrm{C}(\mathrm{t}) \mathrm{W}(\mathrm{t}) \operatorname{Pr}(\mathrm{T}(\mathrm{y}) \geq$ t) $d t$

$E \int_{0}^{\infty} e^{-\delta t} C(t) W(t) d t=\int_{0}^{\infty} e^{-\delta t} C(t) W(t){ }_{t} P_{y} d t$ where $\operatorname{Pr}(\mathrm{T}(\mathrm{y}) \geq \mathrm{t})={ }_{\mathrm{t}} \mathrm{P}_{\mathrm{y}}$

$E \int_{0}^{\infty} e^{-\delta t} C(t) W(t) d t=\int_{0}^{\infty} e^{-\delta t} C(t) W(t) S_{T}(t) d t$

$E \int_{0}^{\infty} e^{-\delta t} C(t) W(t) d t=\int_{0}^{\infty} e^{-\delta t} C(t) W(t) \frac{S_{Y}(y+t)}{S_{Y}(y)} d t$

$E \int_{0}^{\infty} e^{-\delta t} C(t) W(t) S_{Y}(y) d t=\int_{0}^{\infty} e^{-\delta t} C(t) W(t) S_{Y}(y+$ t) $d t$

Defining $\mathrm{C}(\mathrm{t}) \mathrm{W}(\mathrm{t})=\alpha(\mathrm{t})$

$E \int_{0}^{\infty} e^{-\delta t} \alpha(t) S_{Y}(y) d t=\int_{0}^{\infty} \alpha(t) e^{-\delta t} S_{Y}(y+t) d t$,

Following same argument,

$E \int_{0}^{\infty} e^{-\delta t} f(t) d t=\int_{0}^{\infty} f(t) e^{-\delta t}{ }_{t} P_{y} d t$ ， $E \int_{0}^{\infty} e^{-\delta t} f(t) S_{Y}(y) d t=\int_{0}^{\infty} f(t) e^{-\delta t} S_{Y}(y+t) d t$ and $\int_{0}^{\infty} f(t) e^{-\delta t} S_{Y}(y+t) d t=\int_{0}^{\infty} \alpha(t) e^{-\delta t} S_{Y}(y+t) d t$ or $\int_{0}^{\infty} \mathrm{f}(\mathrm{t}) \mathrm{e}^{-\delta \mathrm{t}}{ }_{\mathrm{t}} \mathrm{P}_{\mathrm{y}} d t=$ $\int_{0}^{\infty} \alpha(t) e^{-\delta t}{ }_{t} P_{y} d t$

EQUILIBRIUM CONDITION

This is the equilibrium position and the plan sponsor cannot borrow to pay plan members at retirement. In 
[3], [16] the present value of benefit outgo payable by the trustees equals the present value of total contribution of the plan sponsor so that the equilibrium point is reached. From the equilibrium position,

$\int_{0}^{\infty}[C(t) W(t)-f(t)] S_{Y}(y+t) e^{-\delta t} d t$

$\int_{0}^{b}[C(t) W(t)-f(t)] S_{Y}(y+t) e^{-\delta t} d t$

$\int_{b}^{\infty}[C(t) W(t)-f(t)] S_{Y}(y+t) e^{-\delta t} d t \quad$ but from,

$\int_{0}^{\infty}[C(t) W(t)-f(t)] e^{-\delta t} S_{Y}(y+t) d t=0$

$\int_{0}^{b}[C(t) W(t)-f(t)] S_{Y}(y+t) e^{-\delta t} d t$

$\int_{b}^{\infty}[C(t) W(t)-f(t)] S_{Y}(y+t) e^{-\delta t} d t=0$

$-\int_{0}^{b}[C(t) W(t)-f(t)] S_{Y}(y+t) e^{-\delta t} d t$

$\int_{b}^{\infty}[C(t) W(t)-f(t)] S_{Y}(y+t) e^{-\delta t} d t$

$\int_{b}^{0}[C(t) W(t)-f(t)] e^{-\delta t} S_{Y}(y+t) d t$

$\int_{b}^{\infty}[C(t) W(t)-f(t)] e^{-\delta t} S_{Y}(y+t) d t$

$\mathrm{V}(\mathrm{b})=\int_{\mathrm{b}}^{\infty}\left[\mathrm{e}^{-\delta(\mathrm{b}+\mathrm{t})} \mathrm{C}(\mathrm{t}) \mathrm{W}(\mathrm{t})-\mathrm{e}^{-\delta(\mathrm{b}+\mathrm{t})} \mathrm{f}(\mathrm{t})\right] d \mathrm{t}$

$\frac{\mathrm{v}(\mathrm{b})}{\mathrm{e}^{\delta \mathrm{b}}}=\int_{\mathrm{a}}^{\mathrm{b}}\left[\mathrm{e}^{-\delta \mathrm{t}} \mathrm{C}(\mathrm{t}) \mathrm{W}(\mathrm{t})-\mathrm{e}^{-\delta \mathrm{t}} \mathrm{f}(\mathrm{t})\right] d \mathrm{t}=$

$\int_{b}^{\infty}\left[e^{-\delta t} C(t) W(t)-e^{-\delta t} f(t)\right] d t$. The excess of contributions over the benefit outgo over the interval $0 \leq \mathrm{t} \leq \mathrm{b}$ is the same as the excess of contributions over the benefit outgo over the interval $\mathrm{b} \leq \mathrm{t} \leq \infty$

hence $V(b)=\int_{b}^{\infty}\left[e^{-\delta(b+t)} C(t) W(t)-e^{-\delta(b+t)} f(t)\right] d t$ represents prospective reserve
putting
$\mathrm{a}=0$
in
$\mathrm{V}(\mathrm{b})=$

$\int_{a}^{b}\left[e^{-\delta(b+t)} C(t) W(t)-e^{-\delta(b+t)} f(t)\right] d t$ so that

$\mathrm{V}(\mathrm{b})=\int_{0}^{\mathrm{b}}\left[\mathrm{e}^{-\delta(\mathrm{b}+\mathrm{t})} \mathrm{C}(\mathrm{t}) \mathrm{W}(\mathrm{t})-\mathrm{e}^{-\delta(\mathrm{b}+\mathrm{t})} \mathrm{f}(\mathrm{t})\right] \mathrm{dt}$

represents retrospective reserve

For a new defined benefit scheme just set up, $\mathrm{V}(\mathrm{t})=$ 0 for all integrally whole $t$

$\mathrm{V}(\mathrm{b})=\int_{\mathrm{a}+\mathrm{b}}^{2 \mathrm{~b}}\left[\mathrm{e}^{-\delta \tau} \mathrm{C}(\tau-\mathrm{b}) \mathrm{W}(\tau-\mathrm{b})-\mathrm{e}^{-\delta \tau} \mathrm{f}(\tau-\right.$

b)] $d \tau$, so that $V(a)=0$, makes the integral equation homogeneous.

$\int_{a+b}^{2 b}\left[e^{-\delta \tau} C(\tau-b) W(\tau-b)-e^{-\delta \tau} f(\tau-b)\right] d \tau=0$

Since both $a, b$ are real constant, the integral can be of the form

$\int_{c}^{d}\left[e^{-\delta \tau} C(\tau-b) W(\tau-b)-e^{-\delta \tau} f(\tau-b)\right] d \tau=0$

$e^{-\delta \tau} C(\tau-b) W(\tau-b)-e^{-\delta \tau} f(\tau-b)=0$

$\mathrm{e}^{-\delta \tau} \mathrm{C}(\tau-b) \mathrm{W}(\tau-b)=\mathrm{e}^{-\delta \tau} \mathrm{f}(\tau-b)$. The level contribution rate is

$C(\tau-b)=\frac{e^{-\delta \tau} f(\tau-b)}{e^{-\delta \tau} W(\tau-b)} \quad$ and the total rate of contribution in the interval $0 \leq \tau \leq b$ is
Contribution rate (at time b) = $\frac{\int_{0}^{\mathrm{b}}\left[\mathrm{e}^{-\delta \tau} \mathrm{f}(\tau-\mathrm{b})\right] \mathrm{d} \tau}{\int_{0}^{\mathrm{b}}\left[\mathrm{e}^{-\delta \tau} \mathrm{W}(\tau-\mathrm{b})\right] \mathrm{d} \tau} \quad$ REQUIRED CONTRIBUTION RATE Usually, the rate of contribution is computed for a year interval $\mathrm{k} \leq \tau \leq \mathrm{k}+1$, so that

Contribution rate (at time $\mathrm{k}+1)=\frac{\int_{\mathrm{k}}^{\mathrm{k}+1}\left[\mathrm{e}^{-\delta \tau} \mathrm{f}(\tau-\mathrm{b})\right] \mathrm{d} \tau}{\int_{\mathrm{k}}^{\mathrm{k}+1}\left[\mathrm{e}^{-\delta \tau} \mathrm{W}(\tau-\mathrm{b})\right] \mathrm{d} \tau}$ will be the yearly rate. In practice, assets cannot accumulate at $\delta$, hence the present value integral at equilibrium can only be evaluated in discrete case.

\section{EQUILIBRIUM POSITION OF LIFE INSURANCE USING THIELE'S FIRST ORDER ORDINARY DIFFERENTIAL EQUATION}

$=$ We assume a level premium $\pi$ and we ignore all expenses

$d V(t)=V(t) \delta d t+\pi d t-\mu(t)(1-V(t) d t$

$\frac{\mathrm{dV}(\mathrm{t})}{\mathrm{dt}}=[\delta+\mu(\mathrm{t})] \mathrm{V}(\mathrm{t})+\pi-\mu(\mathrm{t})$

$\frac{\mathrm{dV}(\mathrm{t})}{\mathrm{dt}} \mathrm{e}^{-\int[\delta+\mu(\mathrm{t})] \mathrm{dt}}-[\delta+\mu(\mathrm{t})] \mathrm{V}(\mathrm{t}) \mathrm{e}^{-\int[\delta+\mu(\mathrm{t})] \mathrm{dt}}=$

$\mathrm{e}^{-\int[\delta+\mu(\mathrm{t})] \mathrm{dt}}[\pi-\mu(\mathrm{t})]$

$\frac{\mathrm{dV}(\mathrm{t})}{\mathrm{dt}} \mathrm{e}^{-\left[\delta \mathrm{t}-\log _{\mathrm{e}} \mathrm{l}_{\mathrm{t}}\right]}-[\delta+\mu(\mathrm{t})] \mathrm{V}(\mathrm{t}) \mathrm{e}^{-\left[\delta \mathrm{t}-\log _{\mathrm{e}} \mathrm{l}_{\mathrm{t}}\right]}=$

$\mathrm{e}^{-\left[\delta \mathrm{t}-\log _{\mathrm{e}} 1_{\mathrm{t}}\right]}[\pi-\mu(\mathrm{t})]$

$\frac{\mathrm{d}\left[\mathrm{v}(\mathrm{t}) \mathrm{e}^{-\left[\delta \mathrm{t}-\log _{\mathrm{e}} \mathrm{l}_{\mathrm{t}}\right]}\right]}{\mathrm{dt}}=\mathrm{e}^{-\left[\delta \mathrm{t}-\log _{\mathrm{e}} \mathrm{l}_{\mathrm{t}}\right]}[\pi-\mu(\mathrm{t})]$

$\int_{\mathrm{t}=\mathrm{a}}^{\mathrm{t}=\mathrm{b}} \frac{\mathrm{d}}{\mathrm{dt}}\left[\mathrm{V}(\mathrm{t}) \mathrm{e}^{-\left[\delta \mathrm{t}-\log _{\mathrm{e}} \mathrm{l}_{\mathrm{t}}\right]}\right] \mathrm{dt}=$

$\int_{a}^{b} e^{-\left[\delta t-\log _{e} 1_{t}\right]}[\pi-\mu(t)] d t$

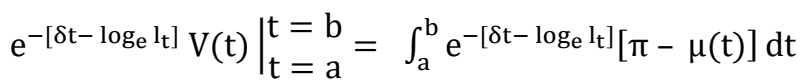
$\mathrm{e}^{-\left[\delta \mathrm{b}-\log _{\mathrm{e}} \mathrm{l}_{\mathrm{b}}\right]} \mathrm{V}(\mathrm{b})-\mathrm{e}^{-\left[\delta \mathrm{a}-\log _{\mathrm{e}} \mathrm{l}_{\mathrm{a}}\right]} \mathrm{V}(\mathrm{a})=$

$\int_{a}^{b} e^{-\left[\delta t-\log _{e} l_{t}\right]}[\pi-\mu(t)] d t$

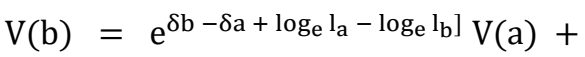
$e^{\left[\delta b-\log _{e} l_{b}\right]} \int_{a}^{b} e^{-\delta t+\log _{e} l_{t}[\pi-\mu(t)] d t}$

$\mathrm{V}(\mathrm{b})=\mathrm{e}^{\delta \mathrm{b}-\delta \mathrm{a}+\log _{\mathrm{e}}\left[\frac{\mathrm{l}_{\mathrm{a}}}{\mathrm{l}_{\mathrm{b}}}\right]} \mathrm{V}(\mathrm{a})+$

$\int_{a}^{b} e^{\delta b-\delta t+\log _{e}\left[\frac{I_{t}}{I_{b}}\right]}[\pi-\mu(t)] d t$

$\mathrm{V}(\mathrm{b})=\mathrm{e}^{\log _{\mathrm{e}}\left[\frac{\mathrm{l}_{\mathrm{a}}}{\mathrm{l}_{\mathrm{b}}}\right]} \mathrm{e}^{\delta \mathrm{b}-\delta \mathrm{a}} \mathrm{V}(\mathrm{a})+$

$\int_{a}^{b} e^{\delta b-\delta t}[\pi-\mu(t)] e^{\log _{e}\left[\frac{l_{t}}{I_{b}}\right]} d t$

$V(b)=\left[\frac{l_{a}}{l_{b}}\right] e^{\delta b-\delta a} V(a)+\int_{a}^{b} e^{\delta b-\delta t}[\pi-\mu(t)]\left[\frac{l_{t}}{l_{b}}\right] d t$

$\mathrm{l}_{\mathrm{b}} \mathrm{V}(\mathrm{b})=\mathrm{l}_{\mathrm{a}} \mathrm{e}^{\delta \mathrm{b}-\delta \mathrm{a}} \mathrm{V}(\mathrm{a})+$

$\mathrm{e}^{\delta \mathrm{b}} \int_{\mathrm{a}}^{\mathrm{b}} \mathrm{e}^{-\delta \mathrm{t}}\left[\pi \mathrm{l}_{\mathrm{t}}-\mu(\mathrm{t}) \mathrm{l}_{\mathrm{t}}\right] \mathrm{dt}$

This is the total reserve for all members aged $b$. 
For a life (y) the integral is of the form $V(y)=f(y)+$ $\lambda \int_{a}^{b} K(y, t) V(t) d t$

and substituting $\mathrm{y}=\mathrm{b}$ in $\mathrm{V}(\mathrm{y})$

$\mathrm{V}(\mathrm{b})=\mathrm{f}(\mathrm{b})+\lambda \int_{\mathrm{a}}^{\mathrm{b}} \mathrm{K}(\mathrm{b}, \mathrm{t}) \mathrm{V}(\mathrm{t}) \mathrm{dt}$

$V(b)=\left[\frac{l_{a}}{l_{b}}\right] e^{\delta b-\delta a} V(a)+\int_{a}^{b} e^{\delta b-\delta t}[\pi-\mu(t)]\left[\frac{l_{t}}{l_{b}}\right] d t$

$\mathrm{f}(\mathrm{b})=\left[\frac{\mathrm{l}_{\mathrm{a}}}{\mathrm{l}_{\mathrm{b}}}\right] \mathrm{e}^{\delta \mathrm{b}-\delta \mathrm{a}} \mathrm{V}(\mathrm{a}), \lambda=\mathrm{e}^{\delta \mathrm{b}}$ and $\mathrm{K}(\mathrm{y}, \mathrm{t})=$

$[\pi-\mu(t)]\left[\frac{l_{t}}{l_{b}}\right], V(t)=e^{-\delta t}$

$\lim _{a \rightarrow 0} V(a)=0$

$\frac{\mathrm{l}_{\mathrm{b}} \mathrm{V}(\mathrm{b})}{\mathrm{e}^{\delta \mathrm{b}}}=\mathrm{l}_{\mathrm{a}} \mathrm{e}^{-\delta \mathrm{a}} \mathrm{V}(\mathrm{a})+\int_{\mathrm{a}}^{\mathrm{b}} \mathrm{e}^{-\delta \mathrm{t}}\left[\pi \mathrm{l}_{\mathrm{t}}-\mu(\mathrm{t}) \mathrm{l}_{\mathrm{t}}\right] \mathrm{dt}$

and taking limit as $\mathrm{b} \rightarrow \infty$, that is

evaluating $\mathrm{l}_{\mathrm{t}} \mathrm{V}(\mathrm{t})$ at maximum terminal age and setting $\mathrm{a}=0$

$\lim _{\mathrm{b} \rightarrow \infty} \frac{\mathrm{l}_{\mathrm{b}} \mathrm{V}(\mathrm{b})}{\mathrm{e}^{\delta \mathrm{b}}}=\mathrm{l}_{\mathrm{a}} \mathrm{e}^{-\delta \mathrm{a}} \mathrm{V}(\mathrm{a})+$

$\int_{0}^{(\omega-y)} e^{-\delta t}\left[\pi l_{t}-\mu(t) l_{t}\right] d t$

$=\quad \lim _{\mathrm{b} \rightarrow \infty}\left\{\mathrm{l}_{\mathrm{a}} \mathrm{e}^{-\delta \mathrm{a}} \mathrm{V}(\mathrm{a})+\int_{0}^{\infty} \mathrm{e}^{-\delta \mathrm{t}}\left[\pi \mathrm{l}_{\mathrm{t}}-\mu(\mathrm{t}) \mathrm{l}_{\mathrm{t}}\right] \mathrm{dt}\right\}=$ $\mathrm{l}_{\mathrm{a}} \mathrm{e}^{-\delta \mathrm{a}} \mathrm{V}(\mathrm{a})+\int_{0}^{\infty} \mathrm{e}^{-\delta \mathrm{t}}\left[\pi \mathrm{l}_{\mathrm{t}}-\mu(\mathrm{t}) \mathrm{l}_{\mathrm{t}}\right] \mathrm{dt}$

$\lim _{b \rightarrow \infty} \frac{l_{b} V(b)}{e^{\delta b}}=0$

$\int_{0}^{\infty} \mathrm{e}^{-\delta \mathrm{t}}\left[\pi \mathrm{l}_{\mathrm{t}}-\mu(\mathrm{t}) \mathrm{l}_{\mathrm{t}}\right] \mathrm{dt}=0$

$\pi \int_{0}^{\infty} \mathrm{e}^{-\delta \mathrm{t}} \mathrm{l}_{\mathrm{t}} \mathrm{dt}=\int_{0}^{\infty} \mathrm{e}^{-\delta \mathrm{t}} \mu(\mathrm{t}) \mathrm{l}_{\mathrm{t}} \mathrm{dt}=\mathrm{l}_{0} \overline{\mathrm{A}_{0}}$

$\pi=\frac{\int_{0}^{\infty} \mathrm{e}^{-\delta \mathrm{t}} \mu(\mathrm{t}) 1_{\mathrm{t}} \mathrm{dt}}{\int_{0}^{\infty} \mathrm{e}^{-\delta \mathrm{t}} \mathrm{t}_{\mathrm{t}} \mathrm{dt}}=\frac{\mathrm{l}_{0} \overline{\mathrm{A}_{0}}}{\int_{0}^{\infty} \mathrm{e}^{-\delta \mathrm{t}} 1_{\mathrm{t}} \mathrm{dt}}=\frac{\overline{\mathrm{A}_{0}}}{\int_{0}^{\infty} \mathrm{e}^{-\delta \mathrm{t}}{ }_{\mathrm{t}} \mathrm{p}_{0} \mathrm{dt}}=$

$\overline{\overline{\mathrm{A}_{0}}} \quad$ REQUIRED LEVEL PREMIUM

This is the premium rate on the life policy payable by the insured

The end result of the $\pi$ is the premium rate on the life policy payable by the insured

\section{CONCLUSION}

The equilibrium position acts as a financial indicator of whether benefits will be defaulted. If the life fund is at equilibrium position, then an income shock at retirement age is avoided. In this paper we have successfully established the actuarial equilibrium position through linear first order integral equation under both defined benefits scheme and life assurance scheme through Thiele's. A further indicator from the reserve function and its derivatives as implied from the equilibrium position is the reserve ratio representing the ratio of the reserve to the annual benefit outgo and expense on the scheme, in other words expressing the amount of current reserves as a percentage of the total amount of actuarial liabilities of the scheme. This relative measure of the reserve is a rough estimate of how long the scheme would run in the event it does not receive contributions and investment earnings. The amount of liabilities represents the present value of future benefits to current pensioners and the total accrued rights of the insured population. Even though funding ratios and contribution requirements are related, they seem to be quite different. Whether a pension fund is $\mathrm{x} \%$ funded benchmark for instance may not necessarily change the opinions of life fund equity and bond market participants because a small rise $\Delta C$ in contribution rate may upset a significant fiscal distress. We have laid a foundation for actuarial exploration of pension and life fund valuation held by a life office on behalf of insured members. The three results obtained re-inforce conventional deterministic approach characterizing funding methods of social insurance scheme.

\section{REFERENCES}

[1]. Collins, P.J. Differential and integral equations, Oxford University Press Inc.,New York, 2006.

[2]. Adeyele J. S \& Olujide J. O. Retirement determinants and money worth ratio of defined contribution pension in Nigeria. The Nigerian Journal of Economic and Social Studies, 58 (3), 411-435., 2016

[3]. Iyer S.. Actuarial mathematics of social security pensions, International Labour office, Geneva, 1999

[4]. Ogungbenle M.G \& J.S. Adeyele J.S. Comparison mechanics of normal cost of fixed pension plans funding policy under projected unit method and entry age method. International journal of Management Sciences Research. 4(1), 355-362, 2018

[5]. Chen G. \& Matkin D.S. T. Actuarial inputs and the valuation of public pension liabilities and contribution requirements: $A$ simulation approach, Center for Retirement Research at Boston College, Hovey House Chestnut Hill., 2017

[6]. Armstrong B \& Zorn P. Designing an adaptive funding policy available at www.grsconsulting.com, 2017. 
[7]. Haberman, S., Booth, P., Chadburn, R., Cooper, D. \& James, D. Modern actuarial theory and practice. London: Chapman \& Hall, 1998

[8]. National Association of State Retirement Administrators (NASRA). 2015. Employee Contributions to Public Pension Plans. https://www.surs.org/pdfs/minutes/Adm_Mar_ 2015_ex7.pdf

[9]. Biggs, A. G. and Richwine, J. The Impact of Act 10 on Public Sector Compensation in Wisconsin . AEI Economic Policy Working Paper 2012-02. Available at SSRN:

https://ssrn.com/abstract $=2239127$ http://dx.doi.org/10.2139/ssrn.2239127

[10]. Novy-Marx, R. \& Rauh. Public pension promises: how big are they and what are they worth? The Journal of Finance 66(4),1211-1249., 2011

[11]. Macdonald S.A: Present values and accumulation, Encyclopedia of actuarial science Volume 3, John wiley \& sons Ltd., 2004

[12]. Polyanin D.A, Manzhirov, V.A. Handbook of integral equations, CRC Press LLC, . Boca Raton, 1998
[13]. Plamondon, P., Drouin, A, Binet, G., Cichon, M., McGillivray, W.R., Bedard, M., PerezMontas, H. Actuarial practice in social security, International Labour office, Geneva., 2002

[14]. Hoem J.M \& Aelen O.O. Actuarial values of payment streams, Scandinavian Actuarial Journal 38-47, 1978

[15]. National Association of State Retirement Administrators NASRA (2015). Public pension plan investment return assumptions. Issue brief. available at: http://www.nasra.org/files/Issue\%20Briefs/NA SRAInvReturnAssumptBrief.pdf

[16]. Accounting Standard (2019). Employee benefits available :https://www.ey.com/Publication/vwLUAssets/ Applying IFRS: IAS 19 Employee Benefits/\$F ILE/Applying $\% 20 I A S \% 2019 \% 20$ Revisions $\% 20$ f or\%20employee\%20benefits.pdf 